\title{
Estimation of the thin ice thickness and heat flux for the Chukchi Sea Alaskan coast polynya from Special Sensor Microwave/Imager data, 1990-2001
}

\author{
Seelye Martin and Robert Drucker \\ School of Oceanography, University of Washington, Seattle, Washington, USA \\ Ronald Kwok and Benjamin Holt \\ Jet Propulsion Laboratory, California Institute of Technology, Pasadena, California, USA \\ Received 12 April 2004; revised 23 July 2004; accepted 3 September 2004; published 26 October 2004.
}

[1] One of the largest Arctic polynyas occurs along the Alaskan coast of the Chukchi Sea between Cape Lisburne and Point Barrow. For this polynya, a new thin ice thickness algorithm is described that uses the ratio of the vertically and horizontally polarized Special Sensor Microwave/Imager (SSM/I) 37-GHz channels to retrieve the distribution of thicknesses and heat fluxes at a $25-\mathrm{km}$ resolution. Comparison with clear-sky advanced very high resolution radiometer data shows that the SSM/I thicknesses and heat fluxes are valid for ice thicknesses less than 10-20 cm, and comparison with several synthetic aperture radar (SAR) images shows that the 10-cm ice SSM/I ice thickness contour approximately follows the SAR polynya edge. For the twelve winters of 1990-2001, the ice thicknesses and heat fluxes within the polynya are estimated from daily SSM/I data, then compared with field data and with estimates from other investigations. The results show the following: First, our calculated heat losses are consistent with 2 years of over-winter salinity and temperature field data. Second, comparison with other numerical and satellite estimates of the ice production shows that although our ice production per unit area is smaller, our polynya areas are larger, so that our ice production estimates are of the same order. Because our salinity forcing occurs over a larger area than in the other models, the oceanic response associated with our forcing will be modified. INDEX TERMS: 4540 Oceanography: Physical: Ice mechanics and air/sea/ice exchange processes; 3360 Meteorology and Atmospheric Dynamics: Remote sensing; 4504 Oceanography: Physical: Air/sea interactions (0312); 4572 Oceanography: Physical: Upper ocean processes; 4207 Oceanography: General: Arctic and Antarctic oceanography; KEYWORDS: Chukchi Sea, coastal polynya, remote sensing

Citation: Martin, S., R. Drucker, R. Kwok, and B. Holt (2004), Estimation of the thin ice thickness and heat flux for the Chukchi Sea Alaskan coast polynya from Special Sensor Microwave/Imager data, 1990-2001, J. Geophys. Res., 109, C10012, doi:10.1029/2004JC002428.

\section{Introduction}

[2] Polynyas are large nonlinearly shaped regions of open water and thin ice occurring within the polar pack ice that persist with intermittent openings and closings at the same location during winter months and recur over many years [Morales Maqueda et al., 2004; Martin, 2002]. The large heat and salt fluxes associated with polynyas play an important role in coupling the atmospheric heat loss with the large-scale ice mass balance and the oceanic salt production. Calculation of these fluxes depends on measurement of the ice thickness distribution within the polynya. One way to retrieve this thickness is with advanced very high resolution radiometer (AVHRR) data. For example, for the St. Lawrence Island polynya, Drucker et al. [2003] use AVHRR data to derive the ice thickness at a $1-\mathrm{km}$ resolution from a combi-

Copyright 2004 by the American Geophysical Union. 0148-0227/04/2004JC002428\$09.00 nation of gridded meteorological data and the AVHRR ice surface temperature (IST) derived from the algorithm of Key and Haefliger [1992] and Key et al. [1997]. Drucker et al. then compare the AVHRR thickness estimates with upward looking sonar (ULS) thickness estimates, and show that for thicknesses less than about $0.5 \mathrm{~m}$, the two estimates agree within experimental error.

[3] Because clouds and the water vapor released from the polynya obscure the surface in the visible/infrared, the AVHRR retrieval is limited to clear days. Given the importance of thin ice to the heat flux estimates, the present paper derives a thin ice algorithm based on the SSM/I (Special Sensor Microwave/Imager) $37 \mathrm{GHz} \mathrm{V} / \mathrm{H}$ ratio, and applies it to the large polynya that occurs in the Chukchi Sea along the Alaska coast. The reason we use $37 \mathrm{GHz}$ rather than $85 \mathrm{GHz}$ is that $37 \mathrm{GHz}$ is much less sensitive to water vapor. This algorithm is validated by comparison with clearsky AVHRR-derived thicknesses and with synthetic aperture radar (SAR). While the 37-GHz retrieved thicknesses 
have only a $25-\mathrm{km}$ spatial resolution, because of the relative immunity of the $37-\mathrm{GHz}$ channel to clouds and water vapor, this approach provides near daily coverage of the ice thicknesses and heat fluxes within the polynya.

[4] Other approaches to polynya investigations include the following. First, Markus and Burns [1995] describe a 37- and $85-\mathrm{GHz}$ algorithm called the Polynya Signature Simulation Method (PSSM), which estimates the polynya properties at a $6.25-\mathrm{km}$ resolution, where the algorithm classifies the pack into three classes: open water, thin ice and first year ice. PSSM is an unusual algorithm, in that it successively applies the $37-$ and $85-\mathrm{GHz}$ data to reduce the effect of clouds on the retrieval, and to take advantage of the high spatial resolution $85-\mathrm{GHz}$ data. From comparison of the PSSM results with Antarctic AVHRR imagery adjacent to Halley station, Markus and Burns [1995] use the AVHRR ice surface temperature and meteorological data taken at Halley station in a manner similar to that described below to show that their thin ice category has an approximate thickness of about $10 \mathrm{~cm}$. Their AVHRR ice thickness analysis [Markus and Burns, 1995, p. 4481] also shows that the polynya includes "ice thicknesses up to $0.15 \mathrm{~m}$." The advantage of this technique is its high spatial resolution; the disadvantage is its division of the polynya ice thicknesses into open water and $10-\mathrm{cm}$ thick ice.

[5] Second, for first year seasonal ice in the Bering Sea, Cavalieri [1994] investigates the distribution of thin ice, using an ice concentration algorithm based on the 19 and $37 \mathrm{GHz}$ polarization and gradient ratio (PR, GR). Because of the formation of a saline layer on the young ice surface, thin ice has a thickness-dependent signature that differs greatly from that of thick ice [Wensnahan et al., 1993]. Cavalieri uses this behavior to derive an algorithm with three tie points, open water, new ice, and first year ice, where his algorithm estimates the relative concentrations of new, young and first year ice within an SSM/I pixel. Because this algorithm depends on both 19 and $37 \mathrm{GHz}$, its resolution is $60 \mathrm{~km}$. The algorithm is also focused on classification of thin ice types (nilas, frazil, gray), so that it does not derive ice thickness. For this algorithm, Cavalieri [1994] and Weingartner et al. [1998, p. 7650] show that the calculated open water areas may include ice with thicknesses as large as $6 \mathrm{~cm}$. Given the dependence of PR, GR on thickness through the surface salinity shown by Wensnahan et al. [1993] and Cavalieri [1994], an alternative to his ice type derivation would have been to retrieve the thin ice thickness.

[6] Third, for polynyas in multiyear ice such as occur in the Arctic Basin, Cavalieri and Martin [1994] use the NASA Team algorithm, which uses the 19 and $37 \mathrm{GHz}$ channels to produce within each pixel, the relative concentrations of open water, first year ice and multiyear ice. In the application of this algorithm, the polynya is defined as a sum of the open water areas in the pixels adjacent to the coast. Unfortunately, Cavalieri [1994, section 3] shows that in the presence of thin ice, this algorithm overestimates the open water concentrations. An alternative approach employed by Weingartner et al. [1998] and Signorini and Cavalieri [2002] is to use Cavalieri's [1994] thin ice algorithm in the coastal polynya regions where multiyear ice may not be important. (These papers do not explicitly give the procedure used to filter multiyear ice.) The problem

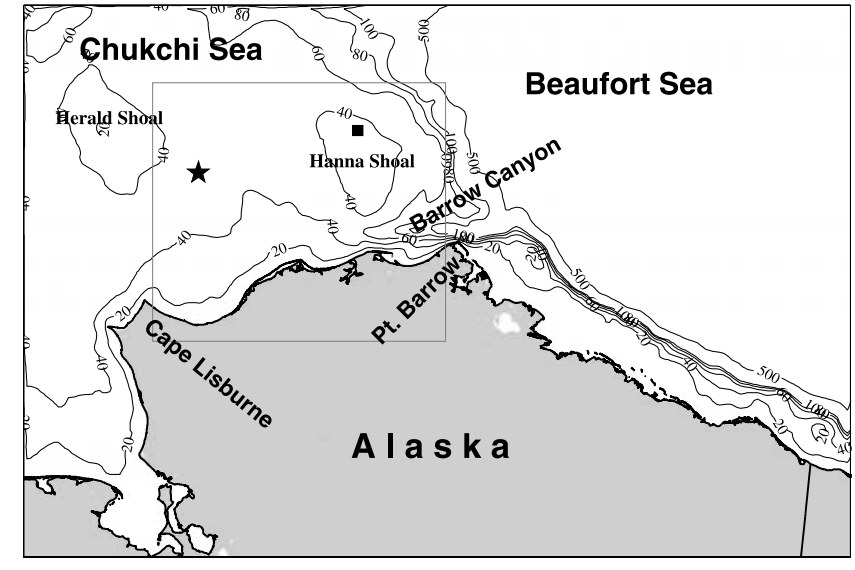

Figure 1. The coastline and bathymetry of the eastern Chukchi Sea. The rectangular box outlines the study area. The small black square shows the location of Katie's Floeberg; the star shows the location of the Weingartner salinity/temperature mooring. The straight-line distance between Cape Lisburne and Point Barrow is approximately $450 \mathrm{~km}$. See text for further description.

with this approach is that heat flux is still assumed to come only from open water, which as we show above, includes ice thicknesses as large as $6 \mathrm{~cm}$, and also ignores the flux from thicker ice. As the handheld aerial photographs of Pease [1987, Figures 9 and 13], the RADARSAT ScanSAR imagery from Drucker et al. [2003], and the imagery presented here show, within polynyas, open water only occurs within about $1 \mathrm{~km}$ of the coast. Further from the coast, the frazil ice forms into Langmuir streaks that fill up with pancake ice and join together in the downwind direction to form a variety of thin ice types that almost completely cover the polynya. This implies that much of the open water observed by the Cavalieri algorithm is actually thin ice.

[7] The present paper argues that given the rapid formation of frazil and pancake ice with distance downwind from the coast, a better, more realistic approach is to model the polynya as containing primarily thin ice with limited open water, rather than as primarily open water. Although as Drucker et al. [2003] discuss, there are disadvantages to the representation of mixtures of frazil, grease and pancake ice as a homogeneous sheet of thin ice, the advantage of this approach is that it allows the algorithm to be validated, since for clear skies, the SSM/I thicknesses can be directly compared with those determined from AVHRR.

[8] Using this approach, the present study examines the large polynya that forms on the Alaskan coast of the Chukchi Sea (Figure 1). There are three reasons for choosing this polynya. First, it is large. In the along-shore direction, it extends about $550 \mathrm{~km}$ along the Alaskan coast between Cape Lisburne to the south and Point Barrow to the north. In the offshore direction, as we show below, it can extend as much $100 \mathrm{~km}$ off the coast. Winsor and Björk [2000] show that this polynya is the largest ice producer north of the Bering Strait; when the Bering Sea is included, it is second in productivity only to the Anadyr Gulf polynya. Second, because the Chukchi polynya forms over the northward lowing Alaska Coastal Current that feeds 


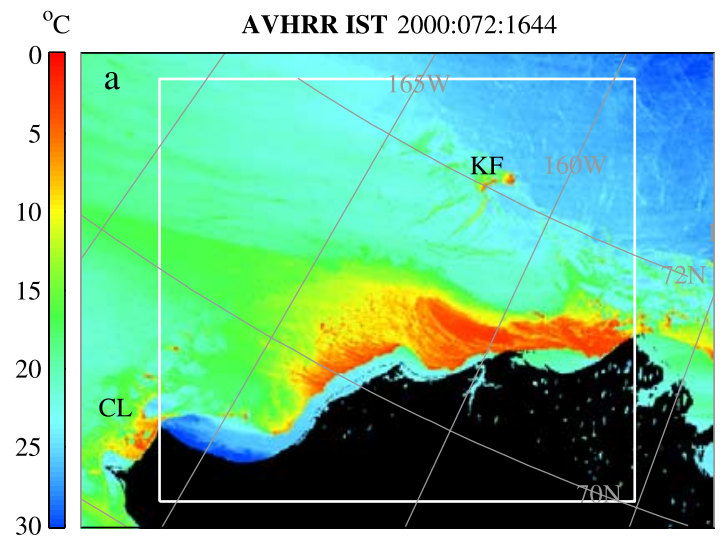

$\mathrm{m}$

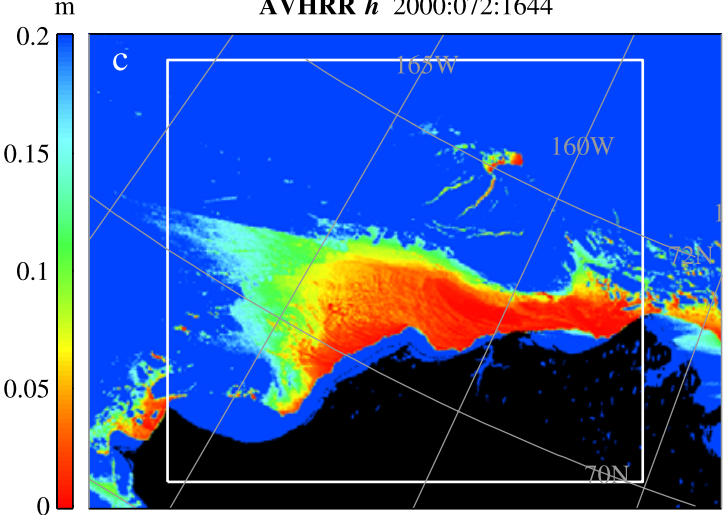

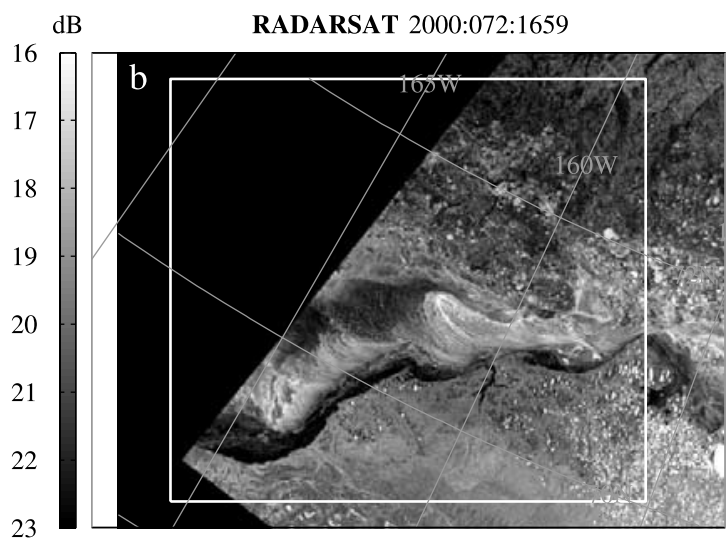

SSM/I T $\mathbf{T}_{\mathbf{B}}$ 37V/H 2000:072

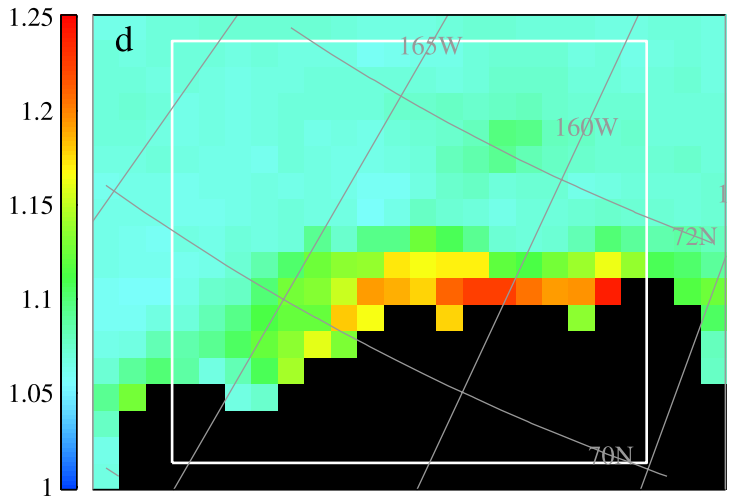

Figure 2. Comparison of AVHRR, RADARSAT and SSM/I imagery for the Chukchi coast polynya on day 72,2000 . The white box outlines the region used in the polynya analysis. (a) The AVHRR ice surface temperature at 1644 UTC. In this image, KF marks the location of the Katie's Floeberg polynya; CL marks the Cape Lisburne polynya. (b) ScanSAR backscatter image at 1659 UTC. (c) The AVHRR ice thickness at 1644 UTC. (d) The daily-averaged SSM/I 37V/H ratio shown with the SSM/I landmask in black. See text for further description.

cold dense water into the Arctic Basin through Barrow Canyon, it is of oceanographic importance. Third, it is well studied. Field studies include Weingartner et al. [1998], and modeling and remote sensing studies include Cavalieri and Martin [1994], Winsor and Björk [2000], Winsor and Chapman [2002], and Signorini and Cavalieri [2002].

[9] In the remote sensing studies of this polynya, Cavalieri and Martin [1994] use the Team (not an acronym) algorithm and Weingartner et al. [1998] and Signorini and Cavalieri [2002] use the Cavalieri [1994] thin ice algorithm. For the Cavalieri and Martin [1994] case and the Signorini and Cavalieri [2002] case, the modeling assumes that all of the heat loss takes place from open water. As shown by Weingartner et al. [1998], to place error bars on the heat fluxes, open water is treated both as open water and as $6 \mathrm{~cm}$ thick ice. Similarly, the numerical modeling studies of Winsor and Björk [2000] and Winsor and Chapman [2002] use a wind-driven model based on Pease [1987], where their models also assume that the heat loss is only from the open water adjacent to the coast.

[10] In the following, section 2 describes the polynya and the ice thickness algorithm, which is derived from the SSM/I $37 \mathrm{~V} / \mathrm{H}$ ratio. The importance of this approach is that because the recently launched AMSR-E on the NASA Aqua satellite has nearly twice the resolution of the SSM/I, a similar approach with AMSR-E will allow resolution of smaller polynyas. Section 3 derives the SSM/I heat flux algorithm, and for a series of clear or partially clear days, compares the AVHRR and SSM/I heat fluxes. Section 4 compares the model with other investigations and for the twelve winters of 1990 to 2001, discusses the behavior of the total heat flux on an annual and a month-by-month basis. Section 5 gives our conclusions.

\section{SSM/I Ice Thickness Algorithm}

[11] As an example of the Chukchi polynya and of the distribution of the $37 \mathrm{~V} / \mathrm{H}$ ratio within the polynya, Figure 2 shows four images of the polynya from AVHRR, SAR and SSM/I for day 72, 2000 (12 March 2000). For the 2000 and 2001 winters, this day had the clearest skies. On this day, the $10-\mathrm{m}$ wind speed was $11 \mathrm{~m} \mathrm{~s}^{-1}$ from $260^{\circ}$ or off the coast, and the 2-m air temperature was $-22^{\circ} \mathrm{C}$. In all cases, our wind data is derived from National Centers for Environmental Prediction (NCEP) surface pressure data; our air temperatures are from International Arctic Buoy Program (IABP) data. The white rectangle outlines our region of interest that extends from Cape Lisburne to Point Barrow, 
which represents a straight-line distance of about $450 \mathrm{~km}$. The top left AVHRR image (Figure 2a) shows the ice surface temperature (IST) derived using the algorithm of Key and Haefliger [1992] and Key et al. [1997]. The image shows three polynyas. The first is the large coastal polynya between Cape Lisburne and Barrow that extends between 25 and $90 \mathrm{~km}$ offshore; the second is a smaller polynya between Point Hope and Cape Lisburne. In the ice interior and at the upper right, there is a third even smaller polynya that forms over Hanna Shoal around a mass of recurrent grounded ice floes that the Canadian Ice Service calls "Katie's Floeberg."

[12] The second image (Figure 2b) shows a RADARSAT ScanSAR image with a $200 \mathrm{~m}$ pixel size taken $15 \mathrm{~min}$ after the AVHRR image. The image shows the bright and dark features within the polynya region that are associated with frazil and pancake ice formation. The bottom left image (Figure 2c) shows the AVHRR-derived ice thickness, processed according to the algorithm of Drucker et al. [2003]. The image shows a large polynya adjacent to the coast, and within the surrounding pack ice to the west, a region of apparent thinner ice that is generated by low-level ice fog being advected out of the polynya. Finally, the bottom right image (Figure 2d) shows the SSM/I 37V/H ratio, where each pixel measures approximately $25 \mathrm{~km}$ square. For future use, we define

$$
R_{37}=\frac{T_{B 37 V}}{T_{B 37 H}},
$$

where the $T_{B}$ are the SSM/I brightness temperatures. The $R_{37}$ ratio compares the relative magnitude of the vertical and horizontal 37-Ghz brightness temperatures, rather than the customarily used polarization ratio $\left(\mathrm{PR}_{19}\right)$ used by the Team and Cavalieri [1994] algorithms. The $\mathrm{PR}_{19}$ is defined as the ratio of the difference and sum of the 19-Ghz vertical and horizontal brightness temperatures. In contrast, $R_{37}$ is the ratio of the vertical and horizontal $37-\mathrm{GHz}$ brightness temperatures, where identically to the PR, the use of this ratio means that variations in surface temperature cancel. The $R_{37}$ is the simplest possible ratio to use in the analysis, and is easily transformed to $\mathrm{PR}_{37}$ through the following equation:

$$
\mathrm{PR}_{37}=\left(R_{37}-1\right) /\left(R_{37}+1\right) .
$$

[13] Figure 2d shows that while the large coastal polynya is easily resolved by the $\mathrm{SSM} / \mathrm{I}$ pixels, at this resolution, the Cape Lisburne and the Katie's Floeberg polynyas are barely visible. In the processing of this image, we deliberately use the daily SSM/I product that is averaged into $25-\mathrm{km}$ bins using the drop-in-the-bucket technique (described at http:// nsidc.org/data/docs/daac/nsidc0001_ssmi_tbs.gd.html). For a specific grid cell, this technique consists of summing the data from all of the daily overpasses, then taking its average. We found that this approach yields better results than the 12-hour EASE grid data, which is taken in both the morning and afternoon. Even though there is a 0.5 pixel $(12.5 \mathrm{~km})$ geolocation error associated with the drop-in-thebucket technique, the EASE grid brightness temperatures are created by resampling the two-dimensional swath data using the antenna pattern to provide the correct weighting.

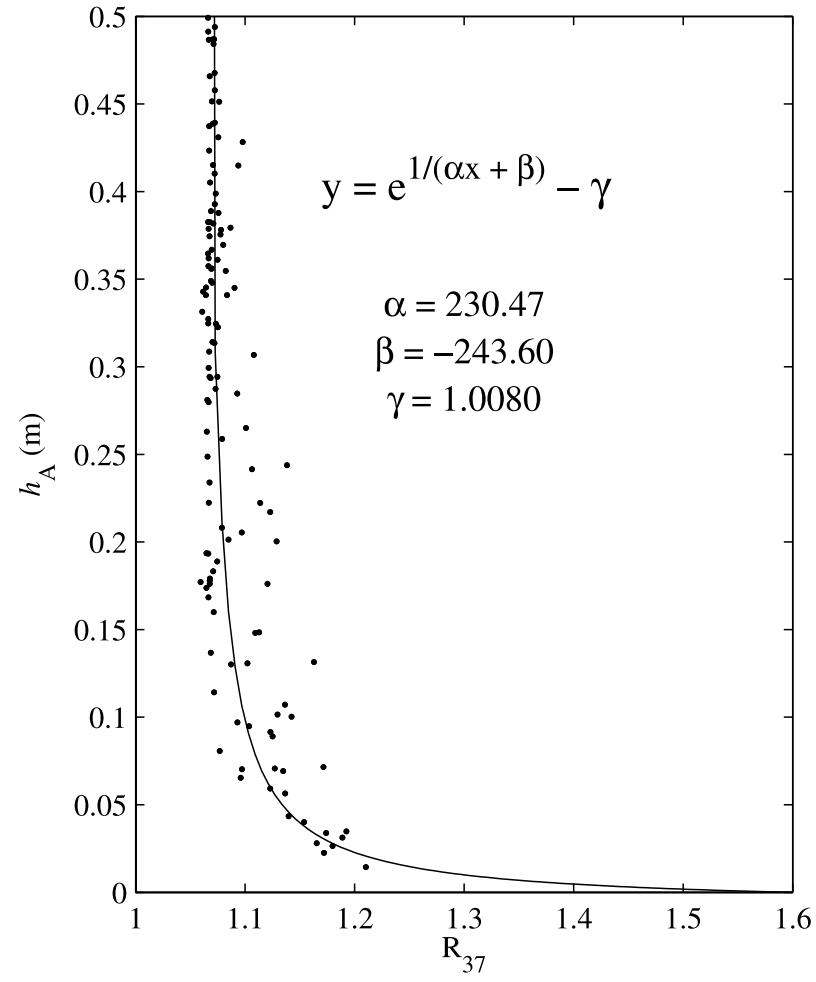

Figure 3. Scatterplot of the AVHRR-derived ice thickness on the vertical axis and the $\mathrm{SSM} / \mathrm{I} 37 \mathrm{GHz} \mathrm{V} / \mathrm{H}$ ratio on the horizontal axis from day 72,2000 , which was the clearest day in our record. The solid curve shows an exponential fit to the data. See text for further description.

Thus there is a smearing of spatial location in the drop-inthe-bucket case, and a smearing of the pixel value in the second. For our purposes, we feel that it is more important to use a field that preserves the observed brightness temperatures and their resolution rather than one with better geolocation characteristics.

[14] Because day 72, 2000, was the clearest day in our record, we use this data to construct the ice thickness algorithm. First, we calculate the AVHRR thicknesses following the method of Drucker et al. [2003], then average these thicknesses into the $25-\mathrm{km}$ blocks that correspond to the $\mathrm{SSM} / \mathrm{I}$ pixels. The AVHRR thicknesses and $R_{37}$ are then plotted versus one another, yielding the scatterplot in Figure 3. Because the AVHRR thickness $h_{\mathrm{A}}$ becomes much less accurate for ice thicker than $0.5 \mathrm{~m}$, Figure 3 shows only data for $h_{\mathrm{A}}<0.5$. Examination of Figure 3 shows the following. First, as $h_{\mathrm{A}}$ increases, $R_{37}$ approaches a vertical asymptote at a value of about 1.1. Second, as $R_{37}$ increases from 1.1, the ice thickness decreases dramatically, approaching a horizontal asymptote. Third, from examination of the adjacent open water in the Bering Sea, open water has a maximum $R_{37}$ of about 1.6. Figure 3 shows, however, that there are no values of $R_{37}$ that approach this limit. This absence probably occurs because the area of the SSM/I pixel is about $625 \mathrm{~km}^{2}$, so that every pixel contains an average of numerous ice types and open water and except in summer, no pixel would be expected to contain only open water.

[15] In the following, we first map the values of $R_{37}$ to $h_{\mathrm{A}}$, then use the derived function to derive the values of the 
Cold high clouds

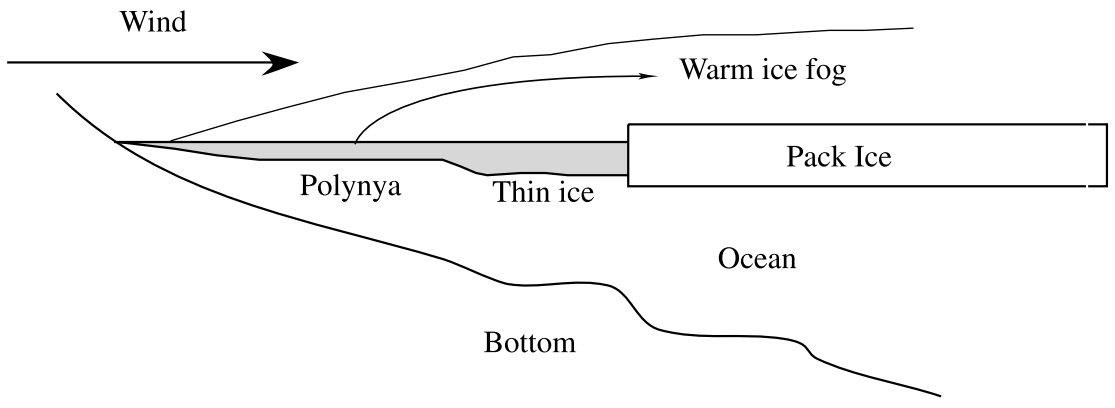

Figure 4. The two kinds of clouds that obscure the polynya region. These are the high cold thin clouds, which make the ice appear colder and thicker than its actual values, and the ice fog or sea smoke generated within the polynya by the vapor flux from thin ice or open water.

$\mathrm{SSM} / \mathrm{I}$ thickness $h_{\mathrm{S}}$. The function used to map the values of $R_{37}$ to ice thickness is the following exponential:

$$
h_{i}=\exp \left[1 /\left(\alpha R_{37}+\beta\right)\right]-\gamma,
$$

where the subscript $i=\mathrm{A}$ or $\mathrm{S}$, depending on whether we are curve-fitting $R_{37}$ to the AVHRR thicknesses or deriving the SSM/I thickness. In the curve fitting and as a first approximation, we assume that $\gamma$ has a value close to unity, so that the curve is asymptotic to zero. After substitution of $\gamma=1$, we define $\hat{h}$ as follows:

$$
\begin{aligned}
\hat{h} & =\alpha R_{37}+\beta \\
& =1 / \log \left(h_{A}+1\right)
\end{aligned}
$$

Linear regression is then applied to $\hat{h}$ to determine $\alpha=$ 230.5 and $\beta=243.6$. Using these values of $\alpha$ and $\beta$, the resulting $h_{A}$ was found to have a value of approximately $8 \mathrm{~mm}$ at $R_{37}=1.6$. For a range of ice thicknesses from 0 to $20 \mathrm{~cm}$, this represents a $4 \%$ discrepancy from the expected value of zero. We correct for this offset by adjusting the value of $\gamma$ from 1 to 1.008 , producing the solid curve shown in Figure 3. We show below in this section that this curve is valid for $R_{37}<1.4$, or for minimum thicknesses of about $5 \mathrm{~mm}$.

[16] A physical justification for this correction is that even though day 72 was our most cloud-free day, the formation of frazil and thin ice within the polynya generates a low-level ice fog. As Walter [1989] shows from aircraft field observations, because this fog is colder than the polynya surface temperature, but warmer than the surrounding pack ice temperature, it increases the apparent AVHRR pack ice surface temperature outside the polynya, but decreases it within the polynya. This means that within the polynya, the AVHRR-retrieved ice thicknesses may be larger than the ice thicknesses measured at the surface. In Figure 3 and for values of $R_{37}$ greater than about 1.1, the effect of this moisture appears as an upward scatter of the data above the curve.
[17] At least two sources of error occur in the comparison of the SSM/I thicknesses with the AVHRR. The first is associated with clouds and fog; the second is associated with the comparison of the daily-averaged SSM/I imagery with an AVHRR image taken at a single time. For the error associated with clouds and fog, Figure 4 shows the two types of clouds that occur. The first consists of the high thin clouds that are advected over the region and are sufficiently thin that they are not always visible. Their effect is to make the ice beneath them appear colder than the actual IST. As described above, the second cloud type consists of the lowlevel ice fog that accompanies the formation of frazil and thin ice within the polynya, and affects the ice thickness both inside and outside of the polynya. Also, in many images, there is an increased cloudiness in the southern part of the polynya adjacent to the Cape Lisburne peninsula. These clouds are removed with a geographic mask. Finally, the cloud filters are only used in the comparison of the SSM/I and AVHRR thicknesses and fluxes; when the SSM/I estimates are used alone, they are unfiltered.

[18] Although it is impossible in this comparison to remove completely the impact of clouds on surface temperature, our cloud filters work as follows. For high thin clouds, exclusion of any pixels with AVHRR ice thicknesses greater than a threshold, such as 10 or $20 \mathrm{~cm}$, removes anomalously thick ice from within the polynya. Although this filter does not exclude any ice thinner than the threshold, it reduces the effect of high clouds. Second, the ice fog that is advected outside of the polynya region can reduce the AVHRR-retrieved thickness of the surrounding pack ice to values less than the threshold. This effect is removed by exclusion of all SSM/I thicknesses greater than the threshold. Also, as Figure 2 shows, there is a region of landfast ice adjacent to the coast, which lies outside of the SSM/I mask. To eliminate the pixels contaminated by landfast ice, the land mask was enhanced by a pixel-bypixel masking of the fast ice.

[19] The second source of disagreement between the retrievals occurs because the AVHRR image consists of a snapshot taken at a specific time, while the SSM/I is the 
daily average of the ascending and descending passes. Although our assumption is that the general shape of the polynya remains stable within a 24 -hour period, it is unlikely that during this period, the downwind edge of the polynya remains at a constant location. Given the nature of the polynya and its volatility in response to wind, we expect that the pixels adjacent to the downwind edge of the polynya have the following properties. First, they are associated with larger thicknesses; second, because of the movement of the polynya boundary in response to variable winds, they are sites where the ice thickness error is greatest. A detailed comparison of the AVHRR and SSM/I thicknesses found this to be the case, in that the thicknesses derived from the pixels along the ice edge have much greater scatter than those in the polynya interior. Because of these problems with pixels located near the outer polynya boundary, we restrict our error analysis to pixels from the central core of the polynya. To define this region, we first define a mask such that pixels are within the polynya if both $h_{\mathrm{A}}$ and $h_{\mathrm{S}}$ are less than $20 \mathrm{~cm}$, where $h_{\mathrm{A}}$ is taken from the AVHRR image, and $h_{\mathrm{S}}$ is from equation (1). We then subdivide this mask into two regions, the polynya core and the polynya edge. This is accomplished objectively by convolving the polynya mask with a $3 \times 3$ kernel $k$, where

$$
k=\left[\begin{array}{ccc}
\sqrt{2} & 1 & \sqrt{2} \\
1 & 0 & 1 \\
\sqrt{2} & 1 & \sqrt{2}
\end{array}\right] .
$$

[20] This kernel is designed so that each element of $k$ is inversely proportional to its distance from the center. When the polynya mask (consisting of 0 's for polynya pixels, 1 's for nonpolynya pixels) is convolved with $k$, the resulting matrix $C$ consists of values ranging between 0 to $s$, where $s$ is the sum of the elements of $k$. Pixels where $C=0$ are entirely enclosed in the polynya; pixels where $C=s$ are entirely outside the polynya. From a variety of experiments, we define the core to consist of those pixels where $C<2$, and the polynya edge to consist of those pixels where $2 \leq C<s$. Thus a pixel that is directly adjacent to two or more pixels outside of the polynya, or which is directly adjacent to one outside pixel and diagonally adjacent to two outside pixels, is considered to lie on the edge of the polynya and is not included in the error analysis.

[21] Figure 5 shows scatterplots of the AVHRR versus SSM/I data for day 72 , for two other relatively clear days, days 348 and 349, and for the combined 3 days. For each row, the left-hand column gives the relation between $h_{\mathrm{A}}$ and $R_{37}$, where for each plot, the solid line shows the day 72 exponential fit to the data. For the top three plots and for points in the core and at the edge, the map inset shows the polynya core (dark gray) and edge (light gray) regions for that day. Examination of days 348 and 349 show that in contrast with day 72 , the AVHRR-thicknesses correspond to values of $R_{37}$ approaching 1.4.

[22] For the core pixels only, the plots in the right-hand column of Figure 5 show the values of $h_{\mathrm{A}}$ and $h_{\mathrm{S}}$. The solid $45^{\circ}$ line is the line of perfect agreement; the adjacent dashed lines enclose the \pm 1 standard deviation of the data, offset by the mean of the error (the bias). The day 72 plot shows that the interior pixels have thicknesses between 0 and $5 \mathrm{~cm}$, with a standard deviation of about $1 \mathrm{~cm}$. Because the day
348 and 349 images are slightly more cloudy than day 72 , the points on their plots exhibit more scatter, but are still clustered around the regression line, especially for very small values of $h$. The combined plot shows that the data extends up to thicknesses of about $12 \mathrm{~cm}$, and has a standard deviation of about $2 \mathrm{~cm}$, which improves with decreasing thickness.

[23] Another way to calculate the error associated with the curve shown in Figure 3 is based on the assumption that the brightness temperatures each have a random error of $0.5^{\circ} \mathrm{K}$. For this case, the increase in error with thickness is easily calculated. For a thickness of $5 \mathrm{~cm}$, the random error is $\pm 0.3 \mathrm{~cm}$; for a thickness of $10 \mathrm{~cm}, \pm 1 \mathrm{~cm}$; for $15 \mathrm{~cm}$, $\pm 2 \mathrm{~cm}$; and for $20 \mathrm{~cm}, \pm 3 \mathrm{~cm}$, so that the random error increases rapidly with thickness. This demonstrates that the error increases with ice thickness. Because the actual result for $5 \mathrm{~cm}$ or less is $\pm 1 \mathrm{~cm}$, the errors associated with the observations overwhelm those associated with the brightness temperatures.

[24] Comparison of the $10-\mathrm{cm}$ ice thickness contour derived from the SSM/I with the ScanSAR imagery provides an additional estimate of the algorithm accuracy. The reason we use ScanSAR imagery in this comparison instead of the ice thickness products of the RADARSAT Geophysical Processor System (RGPS) is due to the RGPS time and spatial limitations. The RGPS tracks ice features away from the coast at three-day intervals [Kwok, 1998]. This relatively large time step, compared with the time scales of the polynya dynamics and the inability of RGPS to track features near the coast, makes the RGPS inappropriate for polynya work. Figure 6 shows the SAR images of the polynya for days $68,71,72$ and 75,2000 . In these images, the polynya is visible because of the large backscatter from the pancake ice and Langmuir streaks. The solid white line outlines the SSM/I area for which the ice thickness is less than or equal to $10 \mathrm{~cm}$. Examination of the images shows that with some differences that are probably associated with the difference between the daily average SSM/I data and the ScanSAR snapshot, the $10-\mathrm{cm}$ contour tends to outline the polynya.

\section{Comparison of the SSM/I and AVHRR Heat Fluxes}

[25] Given the SSM/I ice thickness from equation (1), the heat flux is derived as follows. First, for each pixel, the heat flux through the ice must equal the atmospheric flux to the ice surface, where in the absence of AVHRR data, the unknown fluxes depend on the IST. To derive IST under these conditions, and because we are only interested in thin ice, we use the following procedure. From Markus and Burns [1995], we assume that the interior temperature profile of the ice is linear, where its lower boundary is assumed to be at the seawater freezing point and its upper boundary is at the unknown IST. This assumption of a linear temperature profile within the ice is crucial to our model, which approximates a variety of thin ice categories such as frazil, grease and pancake ice as a uniform ice sheet. We also assume that there is no snow cover. From the SSM/I, we obtain the ice thickness at a $25-\mathrm{km}$ resolution. We then construct a lookup table of the fluxes within the ice and atmosphere as a function of the unknown IST, where the 

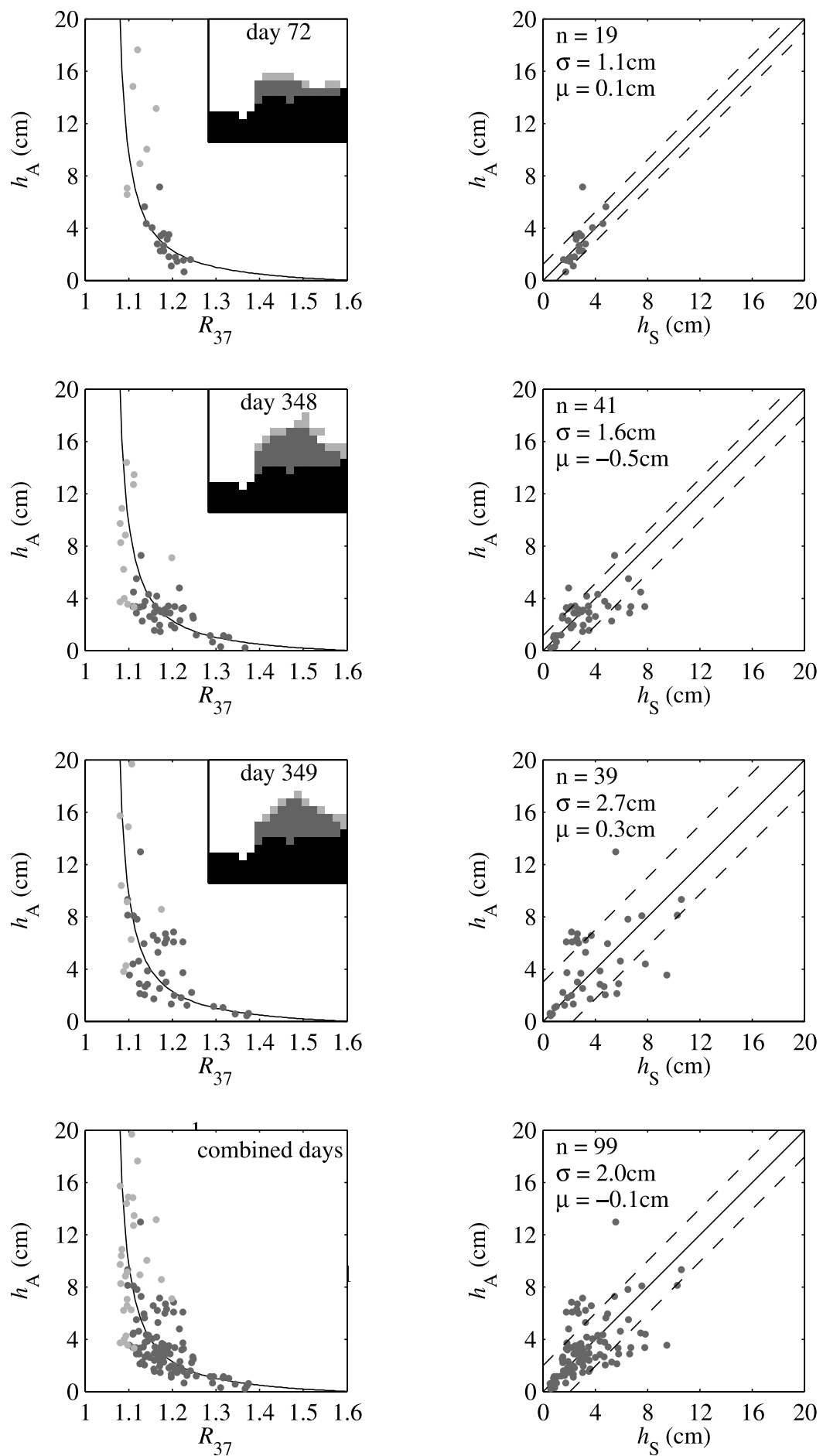

Figure 5. Dependence of $h_{\mathrm{A}}$ on $R_{37}$ (left-hand column), and on $h_{\mathrm{S}}$ (right-hand column) for days 72,348 and 349, and for all 3 days. The dark gray points are within the polynya core; the light gray points lie on the polynya edge. The right-hand plots show points only from the polynya core, where the solid $45^{\circ}$ line is the line of perfect agreement; the adjacent dashed lines show the standard deviation. See text for further description.

atmospheric flux is calculated from the meteorological data for the same day, specifically the air temperature and wind speed, using the algorithm described by Drucker et al. [2003] and Martin et al. [1998]. We determine the heat flux from that value of the IST where the atmospheric and ice heat fluxes are equal. Then, for each day, the total polynya heat loss is calculated by summation of the heat fluxes for each pixel within the thin ice region.

[26] For the AVHRR and SSM/I data, Figure 7 applies the heat flux algorithm and cloud masks to day 72 . The first column shows the AVHRR data; the second, the SSM/I data. The top row shows the AVHRR and the SSM/I 

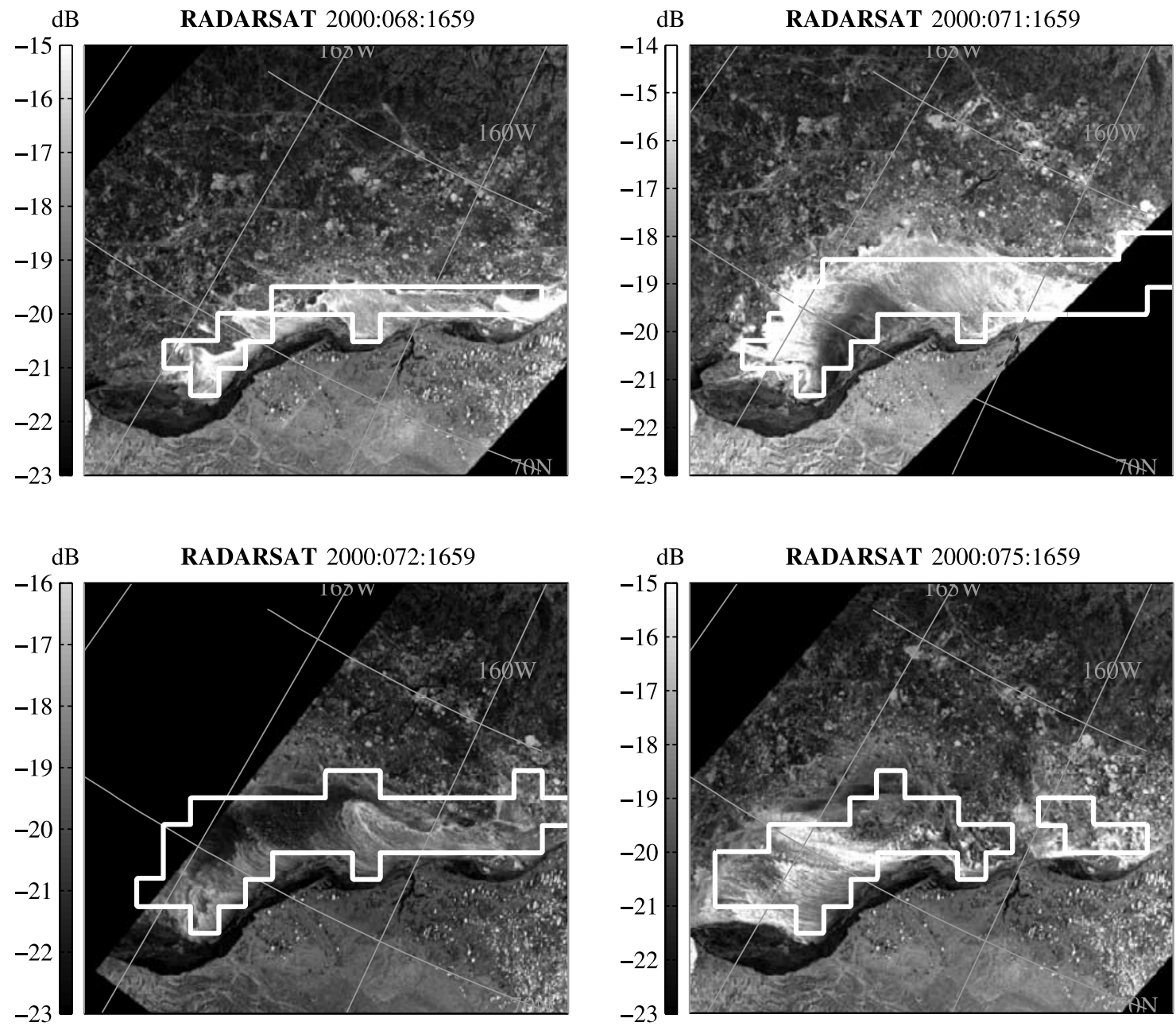

Figure 6. RADARSAT ScanSAR image of the Chukchi polynya for days 68, 71, 72 and 75, 2000, collected at the times shown on each frame. The solid white line outlines the SSM/I area for which the ice thickness is less than or equal to $10 \mathrm{~cm}$.

thicknesses, both at a $25-\mathrm{km}$ resolution and averaged to the $\mathrm{SSM} / \mathrm{I}$ grid. During this period of strong winds, the AVHRR image shows the effect of the warm plume generated by the ice fog blowing off the coast. The second row shows the AVHRR and SSM/I heat fluxes. For this and the following images, the numbers in the small inset boxes at the bottom of each plot show the total heat loss within each image. The third row shows in gray, those pixels that are eliminated by setting the AVHRR thickness threshold at $20 \mathrm{~cm}$. This eliminates the Katie's Floeberg polynya, and a few of the interior polynya pixels. The bottom row shows in pink, those pixels masked by the ice fog filter, which eliminates all SSM/I pixels greater than $20 \mathrm{~cm}$. As examination of the series of images shows, as the cloud masks are applied, the heat fluxes tend toward agreement.

[27] Given that the accuracy of the ice thickness algorithm decreases with increasing ice thickness, why is this comparison so good? As a partial answer to this question, Figure 8 displays the details of the heat losses for the partially clear days 67-75 in 2000 with the cloud filters applied. Figures $8 \mathrm{a}$ and $8 \mathrm{~b}$ show the dependence of the heat loss from each pixel on ice thickness, where the AVHRR is at $1-\mathrm{km}$ resolution, the $\mathrm{SSM} / \mathrm{I}$ is at $25-\mathrm{km}$. As expected, Figures $8 \mathrm{a}$ and $8 \mathrm{~b}$ show that the heat fluxes decrease with increasing ice thickness. They also show that the fluxes lie on families of curves, each representing a day with a different air temperature. Figures $8 \mathrm{c}$ and $8 \mathrm{~d}$ show the cumulative heat flux plotted versus ice thickness for the two instruments, and illustrate one reason for the success of the algorithm. Specifically, the AVHRR cumulative heat loss in Figure $8 \mathrm{c}$ shows that within the unmasked polynya pixels, $60 \%$ of the heat loss comes from ice with thicknesses less than $5 \mathrm{~cm}$, and that about $90 \%$ of the loss comes from ice with thicknesses less than $10 \mathrm{~cm}$. The SSM/I heat loss in Figure 8d has a comparable dependence on thickness. Because most of the heat loss is from ice less than $10 \mathrm{~cm}$ thick, even though the algorithm accuracy decreases with increasing thickness, the two methods yield comparable results. Given the goodness of the thickness comparisons shown in Figure 6 and the fact that ice thicknesses of $10 \mathrm{~cm}$ or less contribute the majority of the heat loss, in the following, we restrict our definition of a polynya to ice thicknesses less than or equal to $10 \mathrm{~cm}$.

[28] For the 2000 and 2001 winters, Figure 9 applies the cloud filters and compares the AVHRR and SSM/I heat fluxes for a selection of partially clear AVHRR images. For days $68-75$, Figure 9a shows the total heat loss plotted 

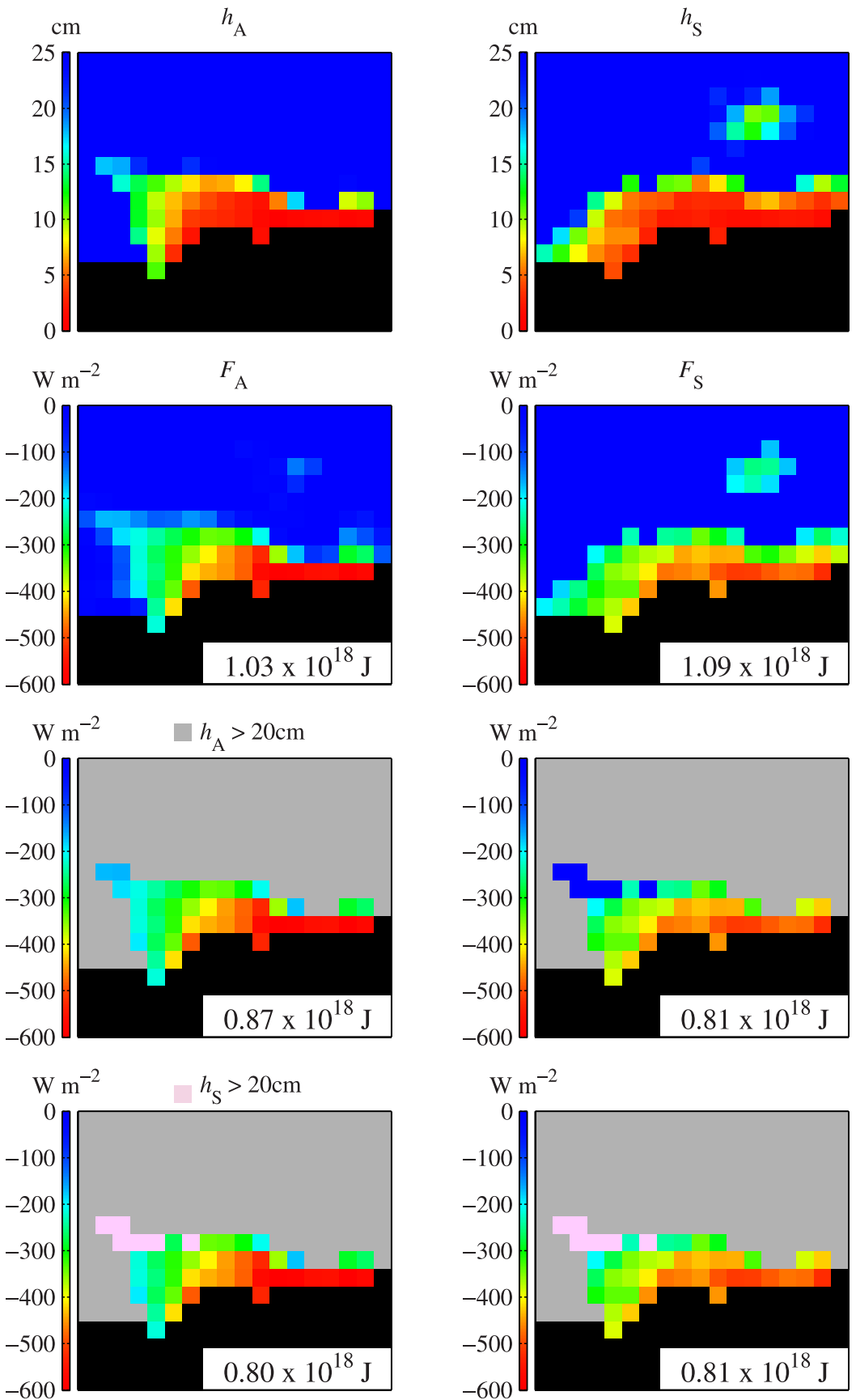

Figure 7. Application of successive masks to the AVHRR (left side) and SSM/I (right side) imagery for day 72. The first row compares the AVHRR and SSM/I thicknesses, where the AVHRR thicknesses have been averaged to the SSM/I 25-km pixels. The second row shows the AVHRR and SSM/I heat fluxes, where for each panel, the number in the white inset box gives the total heat flux for each image. The third row shows the heat flux images with those pixels masked in gray having 25-km AVHRR ice thicknesses greater than $20 \mathrm{~cm}$. The fourth row shows the images with those pixels masked in pink having SSM/I ice thicknesses greater than $20 \mathrm{~cm}$.

versus time with the cloud filters applied, where the solid line shows the AVHRR heat loss, the dashed line shows the $\mathrm{SSM} / \mathrm{I}$ heat loss. Figure $9 \mathrm{~b}$ shows the scatterplots of the total daily heat losses, compared with a best fit $45^{\circ}$ line. Compared with the AVHRR, the SSM/I has a positive bias of $0.07 \times 10^{17} \mathrm{~J}$, an RMS error of $0.3 \times 10^{17} \mathrm{~J}$, corresponding to a percentage error of $16 \%$. For days 348 to 362 , Figures $9 \mathrm{c}$ and 9d show from similar comparisons that the SSM/I has an identical bias and RMS error, but a percentage error of $30 \%$. Although the agreement between the two estimates appears excellent, because the number of pixels in each comparison is the same, the two estimates are not independent, rather they have a component that varies with their common area.

[29] To examine the agreement with the area dependence removed, Figure 10 compares the average heat flux within the polynya from the two different estimates. In this figure 

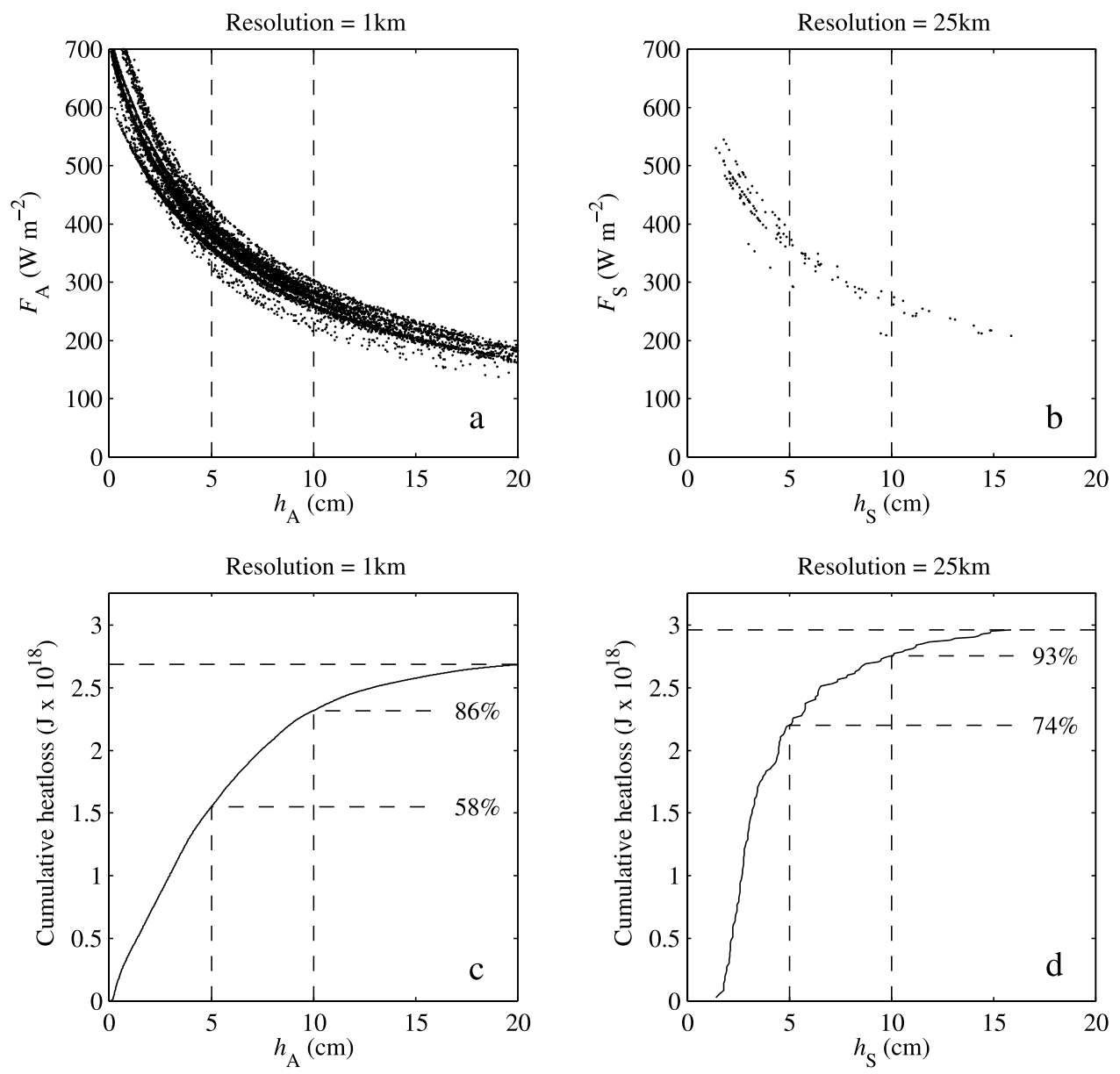

Figure 8. Comparison of the AVHRR and SSM/I heat fluxes on a pixel-by-pixel basis for days 67-75, 2000 , where both sets of images are cloud masked. (a) The AVHRR heat fluxes $\left(F_{\mathrm{A}}\right)$ at a 1-km resolution plotted against thickness. (b) The SSM/I fluxes $\left(F_{\mathrm{S}}\right)$ at a $25-\mathrm{km}$ resolution plotted against thickness. (c) The dependence of the cumulative heat flux on thickness for the 1-km resolution AVHRR case.

(d) The cumulative heat flux for the $25-\mathrm{km} \mathrm{SSM} / \mathrm{I}$ case. See text for further description.

and with the AVHRR fluxes averaged into $25-\mathrm{km}$ SSM/I blocks, Figure 10a compares for days $68-75$, the daily averaged heat flux from the SSM/I and AVHRR estimates, and Figure 10b compares the pixel-by-pixel fluxes. In Figure 10a and relative to the AVHRR daily fluxes, the $\mathrm{SSM} / \mathrm{I}$ fluxes have a mean positive bias of about $20 \mathrm{~W} \mathrm{~m}^{-2}$ and an RMS error of about $50 \mathrm{~W} \mathrm{~m}^{-2}$ or $16 \%$. For the same period, Figure 10b shows that the pixel-by-pixel SSM/I fluxes have a positive bias of $10 \mathrm{Wm}^{-2}$, with an RMS error of about $90 \mathrm{Wm}^{-2}$. For days $248-362$, the agreement is not as good; in Figure 10c, the SSM/I fluxes have a positive bias of $60 \mathrm{Wm}^{-2}$ and an RMS error of $80 \mathrm{Wm}^{-2}$ or $30 \%$. Similarly, in Figure 10d, the pixel-by-pixel SSM/I fluxes have a positive bias of $10 \mathrm{Wm}^{-2}$ and an RMS error of $70 \mathrm{Wm}^{-2}$. This general positive bias between the SSM/I and AVHRR fluxes probably occurs because of the effect of the ice fog on the AVHRR ice surface temperature, so that the ice thickness predicted by the AVHRR appear greater than their in situ values.

[30] Finally, in the examination of the SSM/I images alone, there is an error source in the heat flux estimate associated with the $25-\mathrm{km}$ land/fast-ice mask, which by necessity excludes a portion of the coastal open water and thin ice pixels. Unless each image is analyzed on a case-bycase basis, compensation for this error is very difficult. As an example, from a visual comparison of the SSM/I heat flux and ScanSAR image on day 72, we estimate that the $\mathrm{SSM} / \mathrm{I}$ landmask obscures approximately 4.5 pixels or about $2.8 \times 10^{9} \mathrm{~m}^{2}$ of active polynya. From examination of adjacent pixels that are fully offshore, we estimate that the average flux in these missing pixels is $440 \pm 20 \mathrm{~W} \mathrm{~m}^{2}$. For this day, this gives an additional flux of $1.1 \pm 0.05 \times 10^{17} \mathrm{~J}$. Compared with the total SSM/I heat loss of $8.1 \times 10^{17} \mathrm{~J}$, this represents an underestimate of $14 \%$ due to land masking.

\section{Comparison With Other Investigators}

[31] For the Chukchi polynya, this section compares our monthly and annual heat losses as well as other polynya properties with those derived by other investigators. In the heat flux calculation and for each year, we manually determine the start date of freeze-up as that time in November/December when the polynya region becomes completely surrounded by ice. In spring, the stop date occurs when the polynya heat flux goes to zero. We begin with a detailed comparison of our results for the 1994 and 

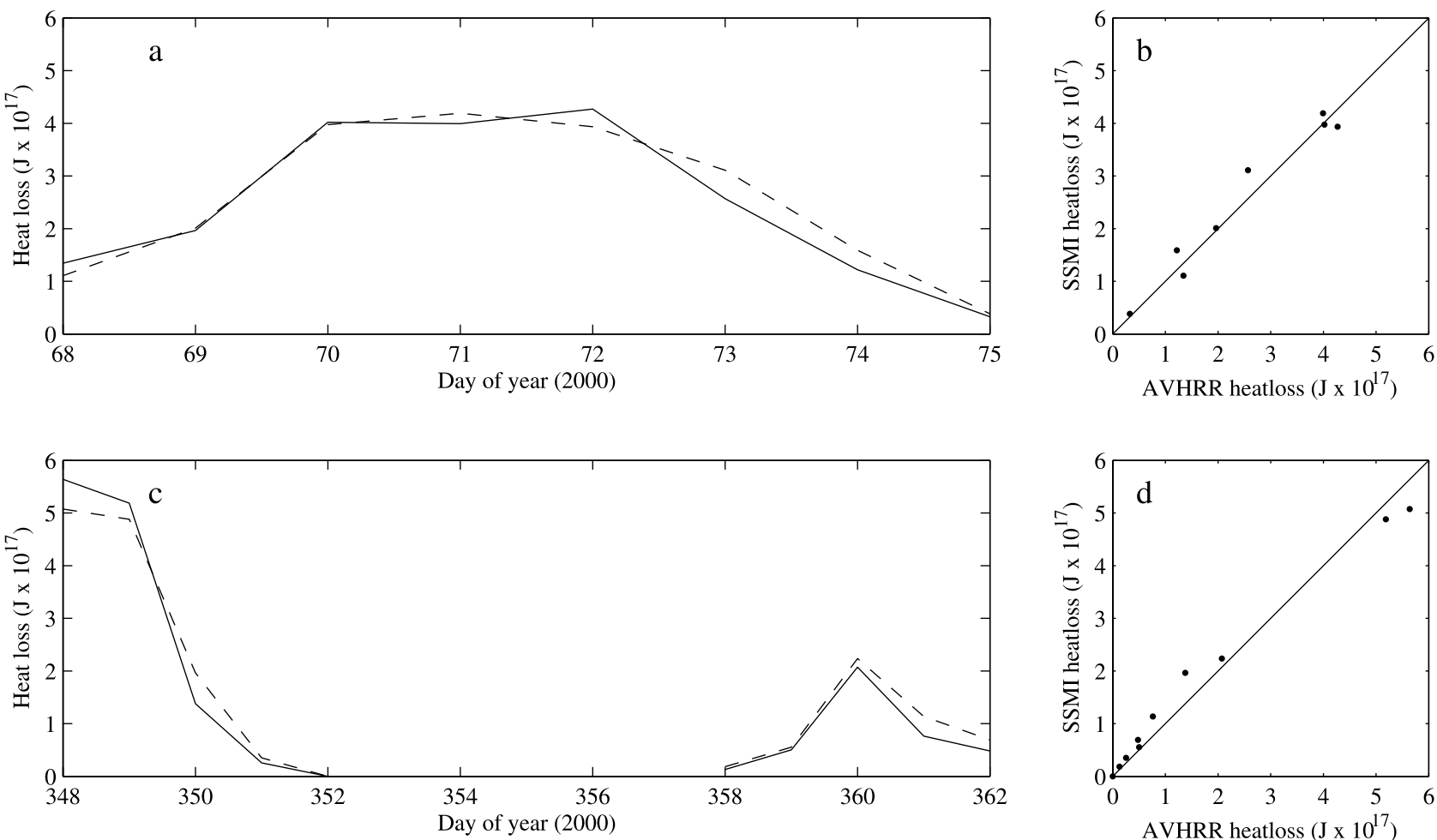

Figure 9. Comparison of the total heat loss for the masked AVHRR and SSM/I polynyas and for partially clear days in 2000. (a) Comparison of the heat losses for days 68-75. (b) The scatterplot of the heat losses for the same period, where the $45^{\circ}$ line is the line of perfect agreement. (c) Comparison of the total heat losses for days 345-362. (d) The scatterplot for the same period. See text for additional information.
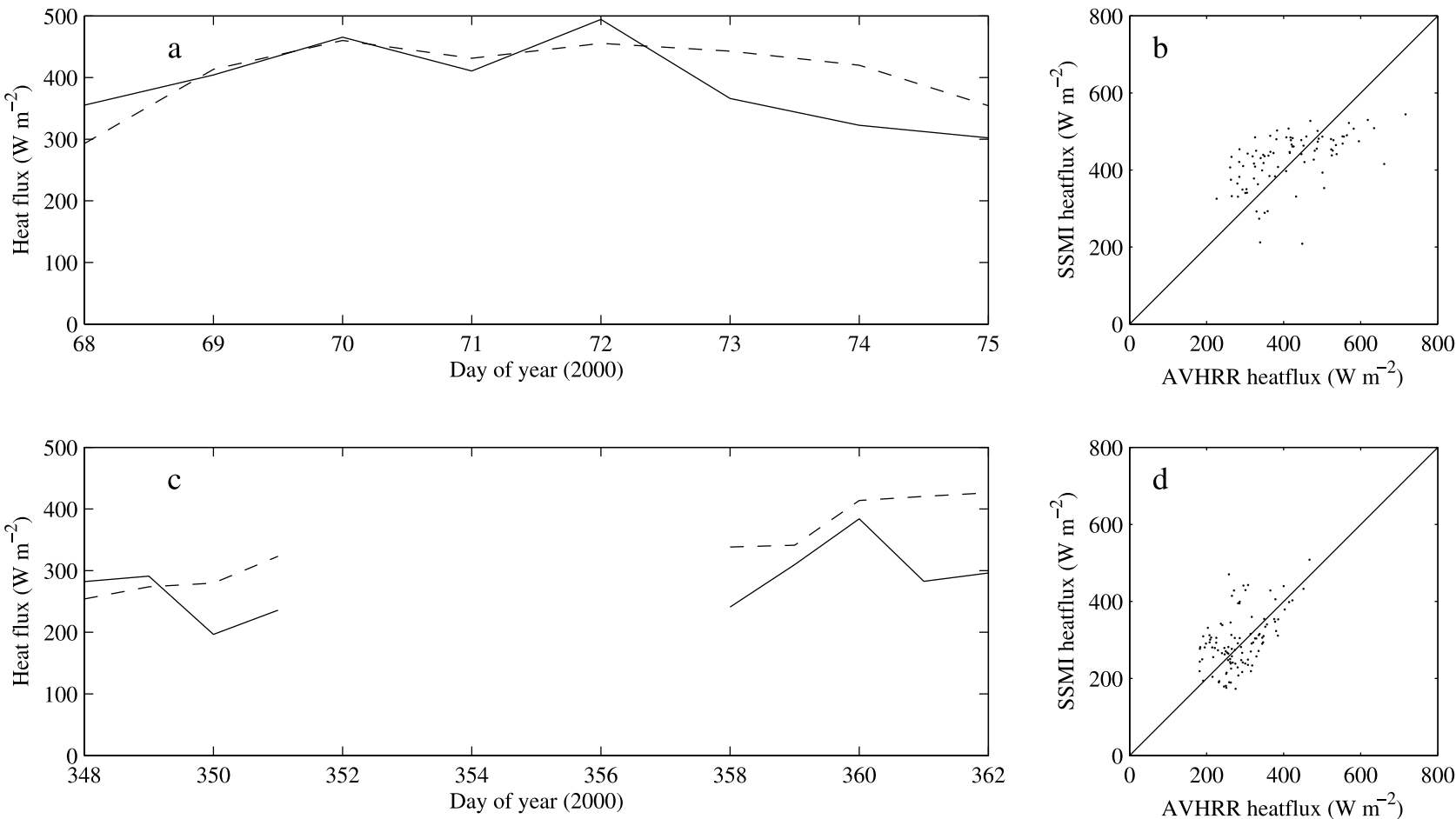

Figure 10. Comparison of the average and pixel-by-pixel SSM/I and AVHRR heat fluxes for two periods in 2000. (a) Comparison of the average heat fluxes for days 68-75. (b) The scatterplot of the pixel-by-pixel heat fluxes for the same period, where the AVHRR fluxes are averaged into 25-km SSM/I blocks and the $45^{\circ}$ line is the line of perfect agreement. (c) Comparison of the average heat fluxes for days 345-362. (d) The pixel-by-pixel scatterplot for the same period. See text for additional information. 

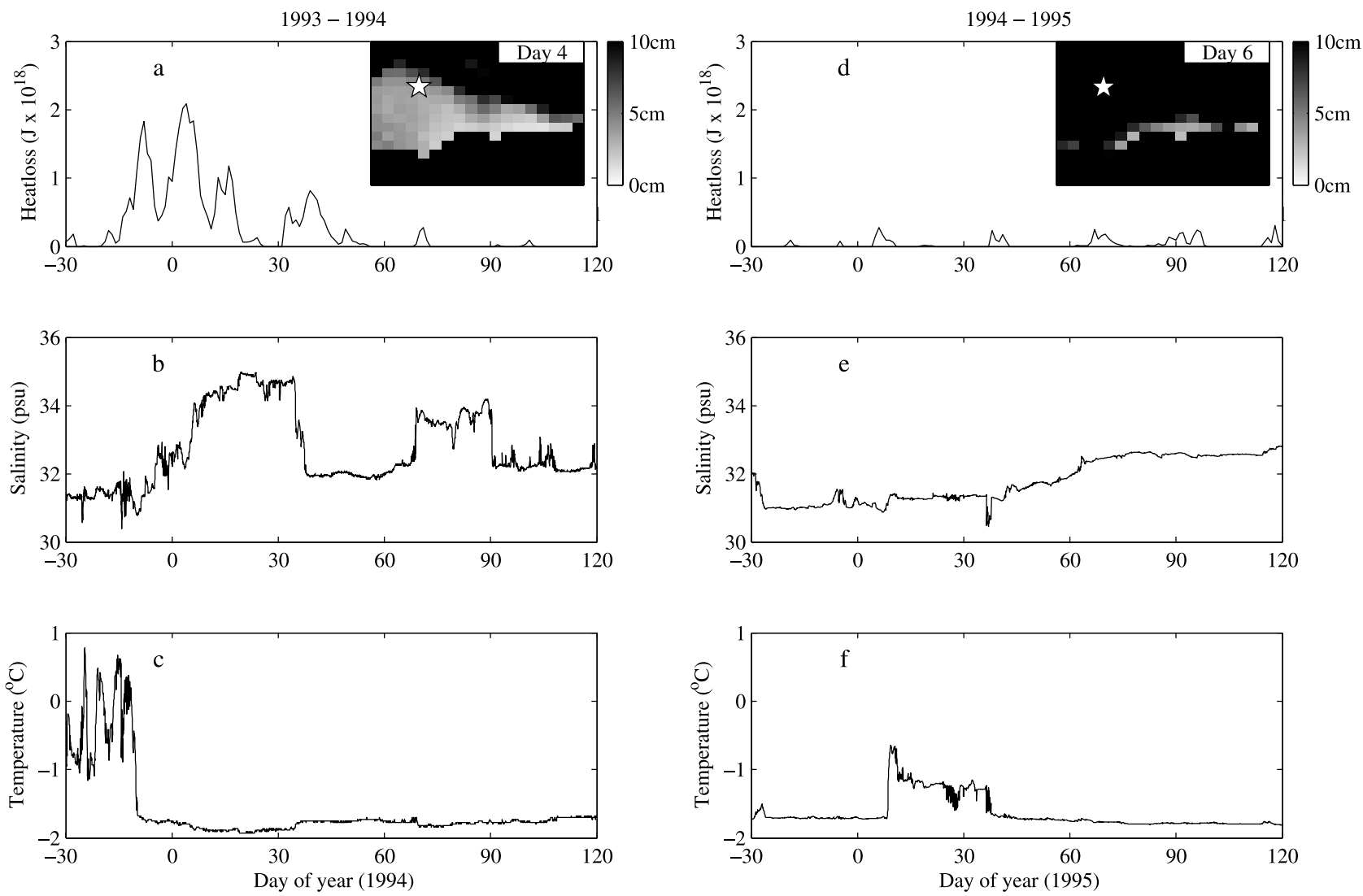

Figure 11. Comparison of the daily polynya heat losses for the winters of 1993-94 and 1994-95 with the salinity and temperature measured at an offshore mooring. (a) The daily heat losses for winter 199394; where the inset shows the thin ice distribution during the day of maximum heat loss. The star on the inset and on Figure 1 shows the mooring location. (b) For the same period, the salinity measured at the mooring. (c) The temperature at the mooring. (d) The daily heat losses for winter 1994-95; where the inset shows the ice distribution during the day of maximum heat loss. (e) For the same period, the salinity at the mooring. (f) The temperature at the mooring.

1995 winters with field measurements of salinity and temperature, then continue with a discussion of the annual heat losses and other polynya properties.

[32] For 1994 and 1995, Figure 11 compares our daily heat flux measurements with salinity/temperature measurements provided by $\mathrm{T}$. Weingartner. These measurements are from a mooring adjacent to the polynya $\left(7037.03^{\circ} \mathrm{N}, 167\right.$ $05.06^{\circ} \mathrm{W}$ ), where the instrument was in $55 \mathrm{~m}$ of water at $5 \mathrm{~m}$ above the bottom. The left-hand column shows the 1994 winter, and the right-hand column shows the 1995 winter. Figures 11a and 11d show the time dependence of the heat loss from those polynyas with thicknesses of $10 \mathrm{~cm}$ or less; the insets show the ice thickness distributions for the day with the largest heat loss, where the star in the inset and in Figure 1 shows the mooring location. Figures $11 \mathrm{~b}$ and $11 \mathrm{e}$ show the salinity at the mooring; Figures $11 \mathrm{c}$ and $11 \mathrm{f}$ show the temperature.

[33] Comparison of the two years shows the dramatic difference in the polynya heat loss and in the salinity and temperature response. For 1994, Figure 11c shows that the water temperature reached the freezing point on about December 20 (day 12), which is nearly coincident with the start of the heat loss time series in 11a. Figure 11a shows that the 1994 ice production occurred in approximately two periods, the first between mid-December and the end of January, the second in February. The largest heat loss occurred on 4 January, for this day, the inset plot shows that the polynya extends over the mooring. The offshore salinity shows a large increase in January through early February and a secondary increase in March. In contrast, for 1995, Figure 11d shows that the ice production and heat loss is negligible, with the polynya never extending over the instrument and with little relation between the heat loss and the small increase in salinity beginning in February 1995 (Figure 11e). Given the negligible ice production, this salinity increase probably originates from advection by the Alaska Coastal Current of more saline water generated in polynyas to the south in the Chukchi and Bering Seas.

[34] As T. J. Weingartner et al. (Circulation on the north central Chukchi shelf, submitted to Deep-Sea Research, 2004; hereinafter referred to as Weingartner et al., submitted paper, 2004) show, one reason for the large difference in response between the 1994 and 1995 winters is the amount of multiyear ice in the Chukchi Sea at the beginning of the 1995 freeze-up. In fall 1993 (winter 1994), much of the Chukchi shelf remained covered with open water through November, so that first year ice formed on the shelf. In contrast, during fall 1994 (winter 1995), advection of 

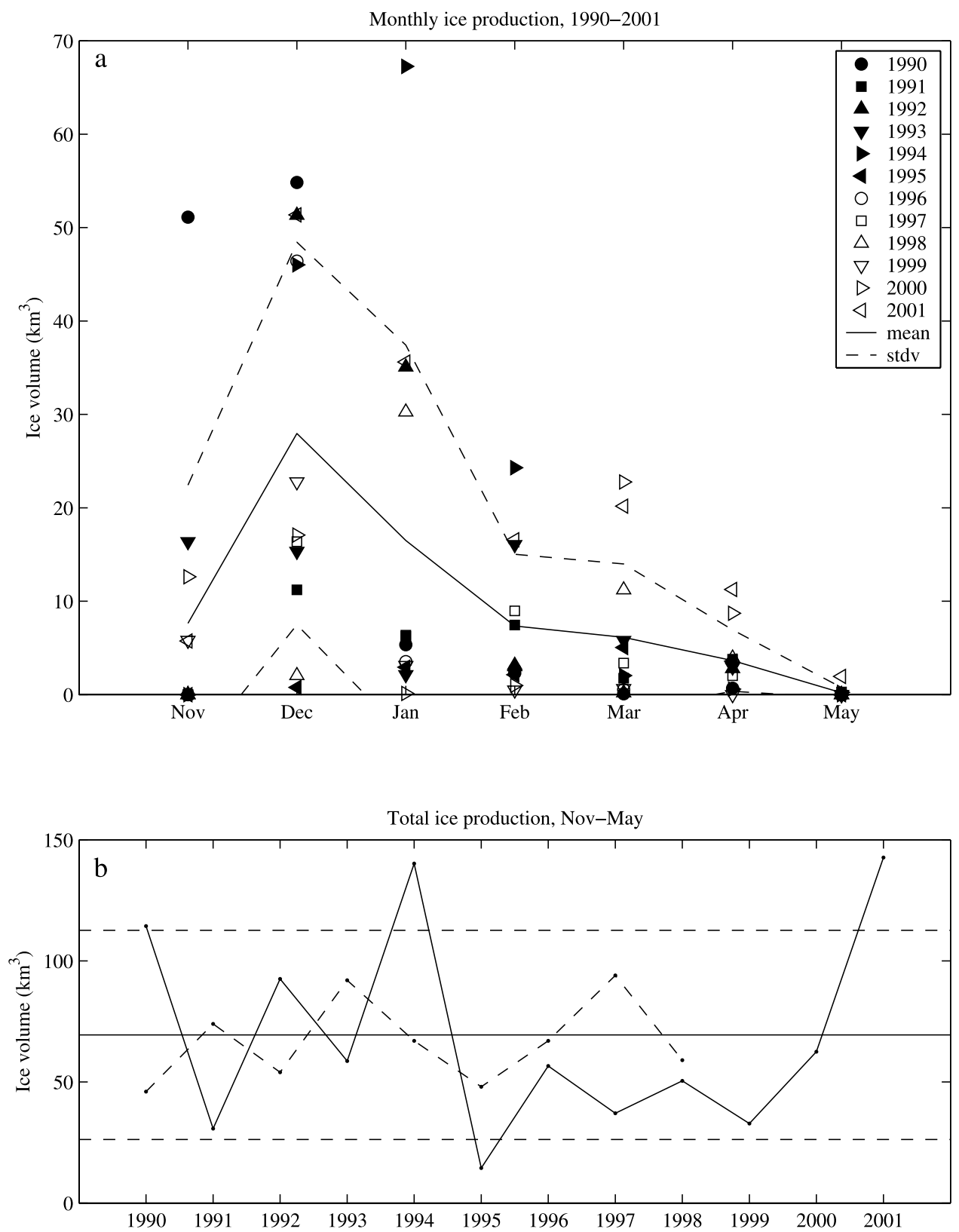

Figure 12. (a) Monthly and (b) annual polynya ice production for the twelve winters of 1990 through 2001. In Figure 12b, the solid line gives our results; the dashed line gives the results of Winsor and Chapman [2002].

multiyear ice into the region insulated the underlying water and increased the mass of ice within the Chukchi, which reduced both the ice advection away from the coast and the polynya growth. As Weingartner et al. (submitted manuscript, 2004) observe, this contributes to the polynya having a much larger ice production in 1994 than in 1995.

[35] For the 1990-2001 winters, the monthly and yearly ice production from the polynya also exhibit several interesting properties. Figure 12 shows the monthly and yearly polynya ice production, where we calculate the ice production from Cavalieri and Martin [1994]. Figure 12a shows the monthly ice production by year. The symbols on the right side of Figure 12a show the year, where, for example, the year 1990 includes November and December 1989, the solid line shows the mean ice production, and the two dashed lines mark the one standard deviation envelope about the mean. The mean shows the characteristic behavior of the ice production, with the growth beginning in November, reaching its maximum in December, then falling off to zero in May. In contrast, a year-by-year examination of the plot shows that the monthly values exhibit considerable variation, with for example, the largest single monthly heat loss occurring in January 1994.

[36] Figure $12 \mathrm{~b}$ and Table 1 compare our annual-averaged polynya properties with the results of Winsor and Chapman [2002], which terminate in 1998. In Figure 12b, the solid line shows our results, the dashed line shows their results. Their results are based on the Pease [1987] model, where 
Table 1. Comparison of the Polynya Properties From the SSM/I Model and the Calculations of Winsor and Chapman [2002] ${ }^{\mathrm{a}}$

\begin{tabular}{|c|c|c|c|c|c|c|c|c|}
\hline \multirow[b]{2}{*}{ Year } & \multicolumn{2}{|c|}{$\begin{array}{c}\text { Ice Growth Per Unit } \\
\text { Area }\end{array}$} & \multicolumn{2}{|c|}{ Mean Polynya Width } & \multicolumn{2}{|c|}{ Maximum Polynya Width } & \multicolumn{2}{|c|}{ Ice Production } \\
\hline & $\mathrm{SSM} / \mathrm{I}, \mathrm{m}$ & $\mathrm{W} / \mathrm{C}, \mathrm{m}$ & $\mathrm{SSM} / \mathrm{I}, \mathrm{km}$ & $\mathrm{W} / \mathrm{C}, \mathrm{km}$ & $\mathrm{SSM} / \mathrm{I}, \mathrm{km}$ & $\mathrm{W} / \mathrm{C}, \mathrm{km}$ & $\mathrm{SSM} / \mathrm{I}, \mathrm{km}^{2}$ & $\mathrm{~W} / \mathrm{C}, \mathrm{km}^{2}$ \\
\hline 1990 & 6.3 & 11 & 33 & 8 & 94 & 37 & 114 & 46 \\
\hline 1991 & 4.4 & 12 & 15 & 13 & 49 & 61 & 31 & 74 \\
\hline 1992 & 5.6 & 12 & 29 & 11 & 151 & 39 & 88 & 54 \\
\hline 1993 & 6.4 & 14 & 20 & 14 & 81 & 37 & 59 & 92 \\
\hline 1994 & 7.2 & 12 & 39 & 12 & 138 & 50 & 140 & 67 \\
\hline 1995 & 3.2 & 9 & 10 & 11 & 29 & 47 & 14 & 48 \\
\hline 1996 & 4.2 & 12 & 22 & 12 & 128 & 42 & 55 & 67 \\
\hline 1997 & 5.2 & 15 & 15 & 14 & 38 & 60 & 36 & 94 \\
\hline 1998 & 6.6 & 9 & 15 & 15 & 54 & 47 & 49 & 59 \\
\hline 1999 & 2.9 & & 30 & & 114 & & 33 & \\
\hline 2000 & 5.9 & & 20 & & 72 & & 62 & \\
\hline 2001 & 11.3 & & 27 & & 75 & & 143 & \\
\hline 9-year mean & 5.4 & 11.8 & 21.9 & 12.2 & 84.6 & 46.7 & 65.1 & 66.8 \\
\hline 9-year $\sigma$ & \pm 1.3 & \pm 2.0 & \pm 9.8 & \pm 2.1 & \pm 45.8 & \pm 9.1 & \pm 41.2 & \pm 17.5 \\
\hline 12 -year mean & 5.8 & & 22.9 & & 85.2 & & 68.6 & \\
\hline 12 -year $\sigma$ & \pm 2.2 & & \pm 8.8 & & \pm 40.3 & & \pm 43.3 & \\
\hline
\end{tabular}

${ }^{\mathrm{a}}$ Winsor and Chapman [2002] results listed as $\mathrm{W} / \mathrm{C}$; $\sigma$ is standard deviation.

the polynya area and width is derived from advection by offshore winds of the surrounding pack ice and the heat loss only occurs from open water. In contrast, our SSM/I algorithm shows no open water, but only thin ice. In Table 1, the first column lists the winter year; the second and third columns list the cumulative ice thickness, where the second gives our result and the third gives the Winsor and Chapman [2002] result. Our definition of the cumulative ice thickness is identical to Winsor and Chapman, who define it as the ice production per unit area for the entire polynya region, integrated only over those days for which polynyas occur. Comparison of the two columns shows that the WinsorChapman result exceeds ours by about a factor of 2 . This is expected because the open water heat flux is much greater than that from thin ice. Similarly, the fourth and fifth columns give the mean polynya width, which following Winsor and Chapman [2002] is defined as the mean daily width averaged only over those days in which polynyas occur. In all cases, our mean widths are greater than theirs, sometimes by as much as a factor of 2-3. From Figure 6, comparison of the $\mathrm{SSM} / \mathrm{I}$ and SAR polynya extents show that the polynya easily extends $50-75 \mathrm{~km}$ off the coast, so that our results appear consistent with observation.

[37] The sixth and seventh columns give the maximum polynya widths. The two approaches define these differently. Winsor and Chapman [2002] choose this quantity as the maximum of the mean daily polynya width; we choose it as mean width for the day with the maximum heat flux. Our reason in making this choice was to eliminate the very large widths that occur for polynyas during spring periods of negligible heat flux. In spite of this difference in definition, comparison of the two columns shows that in most of the years, our widths are again much larger than theirs. The last two columns list the total annual heat loss from each polynya, which Figure $12 \mathrm{~b}$ plots. Finally, at the bottom of Table 1, the top two rows list for each quantity, the 9-year means and standard deviations, corresponding to the period of overlap between the two sets of observations; the bottom two rows list the 12-year means and standard deviations for our results only. In both cases, the mean ice production is about $70 \mathrm{~km}^{3}$ per year. For comparison, Kwok and Rothrock
[1999] find that between 1990 and 1995, the average ice volume flux through Fram Strait is about $2400 \mathrm{~km}^{3}$ per year, so that this polynya produces about $3 \%$ of the exported ice.

[38] Examination of Figure $12 \mathrm{~b}$ and Table 1 shows that even though our ice production is greater than theirs for only three of the nine years, one difference between the two production rates is that our standard deviations are twice theirs. In particular, from the above discussion of the Weingartner field data, we know that 1994 was a large ice production year, while because of the presence of multiyear ice at the beginning of the ice growth season, 1995 was a small ice production year. Table 1 shows that for this 2 -year period, our ice production differs by a factor of 10, and theirs differ by a factor of 1.4. Because their model assumes the offshore ice drift is only a function of wind speed, we suspect that the differences between the two results may in part be caused by the year-to-year changes in the offshore ice conditions. More offshore multiyear ice, for example, would increase the drag, inertia and internal ice stress of the surrounding pack ice and reduce its response to offshore winds, whereas their model assumes a constant response to offshore winds. Another reason for the difference between the two approaches is that our method cannot observe small coastal leads, whereas the Winsor-Chapman approach accounts for such leads. Our method thus discriminates in favor of strong winds and large polynyas. The importance of our result is that the salt flux from the polynya is distributed over a much larger area than in their model. From Gawarkiewicz and Chapman [1995], this change in the salt distribution with distance from the coast will affect the offshore length scale of the oceanic response.

[39] Other calculations of the Chukchi coast polynya heat loss involve the use of the NASA Team algorithm [Cavalieri and Martin, 1994], and the Cavalieri [1994] thin ice algorithm [Weingartner et al., 1998; Signorini and Cavalieri, 2002]. As described in section 1, the Team algorithm overestimates the open water amount, while the Cavalieri algorithm classifies each pixel into different concentrations of open water, which includes ice thicknesses up to about $6 \mathrm{~cm}$, thin ice and first year ice. The Cavalieri algorithm then calculates the heat flux from the open water category alone. 
Because each pixel can contain different concentrations of open water, this model produces a salt flux that decreases with distance from the coast. In spite of this, it has two limitations. First, because it is based on both the 19 and $37 \mathrm{GHz}$ channels, its effective resolution is $60 \mathrm{~km}$, and for pixels adjacent to land, fast ice, or to the first and multiyear ice at the polynya edge, it has a greater ice and land contamination problem than an algorithm using only $37 \mathrm{GHz}$. Second, the heat loss excludes contributions from ice with thicknesses greater than $6 \mathrm{~cm}$.

[40] Specific comparisons between our algorithm and the Cavalieri thin ice algorithm include the following. For the 1992 winter, Weingartner et al. [1998] find a maximum open water area of $26,000 \mathrm{~km}^{2}$, yielding a maximum effective polynya width of $60 \mathrm{~km}$. We call this the effective width because it is the width of the open water area within their polynya box; the actual width of their mixture of thin ice, first year ice and open water can be much greater. They also found an annual ice production of about $75 \mathrm{~km}^{3}$. For the same period, we have a maximum width of $150 \mathrm{~km}$ and an annual ice production of about $90 \mathrm{~km}^{3}$. For the 1997 winter and using the same algorithm, Signorini and Cavalieri [2002] find a maximum open water area of $8000 \mathrm{~km}^{2}$, for a maximum effective polynya width of about $20 \mathrm{~km}$. For the same year, our maximum width was $40 \mathrm{~km}$. Our polynyas tend to be larger in area than those derived either numerically or from the Cavalieri algorithm. This again suggests that the salt flux from our model will be more realistic and distributed over a larger area.

\section{Conclusions}

[41] In summary, the above work shows that our SSM/I thin ice approach provides an effective means for calculation of the daily polynya heat loss at a $25-\mathrm{km}$ resolution that is validated against AVHRR and SAR imagery. It also gives results that qualitatively compare with ocean observations. The method should be adaptable to the Advanced Microwave Scanning Radiometer-EOS (AMSR-E) data, which would provide similar thickness data at twice the resolution. Compared to other investigations, our model produces a larger polynya area, but because of its distribution of ice thicknesses, a relatively smaller cumulative thickness. Our polynyas are also wider than those defined from numerical models or from the Cavalieri [1994] algorithm approach. Comparison with the numerical model of Winsor and Chapman [2002] shows that the result of this more realistic distribution of the thin ice thickness within the polynya means that the salinity forcing instead of being uniform and concentrated near the shore, is instead spread out over a much larger area and decreases with distance from the coast. Because our algorithm depends only on the 37-GHz chan$\mathrm{nel}$, it has a $25-\mathrm{km}$ spatial resolution, compared with the $60-\mathrm{km}$ Cavalieri algorithm resolution, provides for a more realistic salinity flux, and subject to the accuracy of the heat flux algorithm, provides a better distribution of ice growth and salt flux. Because the oceanic response models depend on the width and spatial distribution of the forcing as well as the strength, our approach gives more realistic forcing, and compared to previous models, should generate a more realistic oceanic response.
[42] Acknowledgments. We each gratefully acknowledge the support of the National Aeronautics and Space Administration under NAG5-11057. The JPL effort was supported by NASA through a contract with the Jet Propulsion Laboratory, California Institute of Technology. We thank Kevin Engle of the University of Alaska for providing the AVHRR data used in this study, the Alaska Satellite Facility for providing the SAR data, Tom Weingartner of the University of Alaska for providing the mooring data, and Peter Winsor of the Woods Hole Oceanographic Institution for help in interpreting his model data. We also thank an anonymous reviewer for his comments, and Don Cavalieri for his careful reading of the manuscript and for his contribution to the discussion of $\mathrm{PR}_{37}$ and $R_{37}$. We finally acknowledge that the daily averaged SSM/I data in the polar stereographic grid and the swath data in the EASE grid were obtained from the National Snow and Ice Data Center in Boulder, Colorado.

\section{References}

Cavalieri, D. J. (1994), A microwave technique for mapping thin sea ice, J. Geophys. Res., 99, 12,561-12,572.

Cavalieri, D. J., and S. Martin (1994), The contribution of Alaskan, Siberian, and Canadian coastal polynyas to the cold halocline layer of the Arctic Ocean, J. Geophys. Res., 99, 18,343-18,362.

Drucker, R., S. Martin, and R. Moritz (2003), Observations of ice thickness and frazil ice in the St. Lawrence Island polynya from satellite imagery, upward looking sonar, and salinity/temperature moorings, J. Geophys. Res., 108(C5), 3149, doi:10.1029/2001JC001213.

Gawarkiewicz, G., and D. Chapman (1995), A numerical study of dense water formation and transport on a shallow, sloping continental shelf, J. Geophys. Res., 100, 4489-4507.

Key, J., and M. Haefliger (1992), Arctic ice surface temperature retrieval from AVHHR thermal channels, J. Geophys. Res., 97, 5885-5893.

Key, J., J. Collins, C. Fowler, and R. Stone (1997), High-latitude surface temperature estimates from thermal satellite data, Remote Sens. Environ., $61,302-309$.

Kwok, R. (1998), The RADARSAT Geophysical Processor System, in Analysis of SAR Data of the Polar Oceans: Recent Advances, edited by C. Tsatsoulis and R. Kwok, pp. 235-257, Springer-Verlag, New York.

Kwok, R., and D. A. Rothrock (1999), Variability of Fram Strait flux and North Atlantic Oscillation, J. Geophys. Res., 104, 5177-5189.

Markus, T., and B. A. Burns (1995), A method to estimate sub-pixel scale coastal polynyas with satellite passive microwave data, J. Geophys. Res., $100,4473-4487$

Martin, S. (2002), Polynyas, in Encyclopedia of Ocean Sciences, edited by J. H. Steele, K. K. Turekian, and S. A. Thorpe, pp. 2241-2247, Academic, San Diego, Calif.

Martin, S., R. Drucker, and K. Yamashita (1998), The production of ice and dense shelf water in the Okhotsk Sea polynyas, J. Geophys. Res., 103, $27,771-27,782$

Morales Maqueda, M. A., A. J. Willmott, and N. R. T. Biggs (2004), Polynya dynamics: A review of observations and modeling, Rev. Geophys., 42, RG1004, doi:10.1029/2002RG000116.

Pease, C. H. (1987), The size of wind-driven coastal polynyas, J. Geophys. Res., 92, 7049-7059.

Signorini, S. R., and D. J. Cavalieri (2002), Modeling dense water production and salt transport from Alaskan coastal polynyas, J. Geophys. Res., 107(C9), 3051, doi:10.1029/2000JC000491.

Walter, B. A. (1989), A study of the planetary boundary layer over the polynya downwind of St. Lawrence Island in the Bering Sea using aircraft data, Boundary Layer Meteorol., 48, 255-282.

Weingartner, T. J., D. J. Cavalieri, K. Aagaard, and Y. Sasaki (1998), Circulation, dense water formation, and outflow on the northeast Chukchi shelf, J. Geophys. Res., 103, 7647-7661.

Wensnahan, M., G. A. Maykut, T. C. Grenfell, and D. P. Winebrenner (1993), Passive microwave remote sensing of thin sea ice using principal component analysis, J. Geophys. Res., 98, 12,453-12,468.

Winsor, P., and G. Björk (2000), Polynya activity in the Arctic Ocean from 1958 to 1997, J. Geophys. Res., 105, 8789-8803.

Winsor, P., and D. C. Chapman (2002), Distribution and interannual variability of dense water production from coastal polynyas on the Chukchi Shelf, J. Geophys. Res., 107(C7), 3079, doi:10.1029/2001JC000984.

R. Drucker and S. Martin, University of Washington, School of Oceanography, Box 357940, Seattle, WA 98195-7940, USA. (seelye@) ocean.washington.edu)

R. Kwok and B. Holt, Jet Propulsion Laboratory, California Institute of Technology, 4800 Oak Grove Drive, Pasadena, CA 91109, USA. 